\title{
OPERATIONAL SYSTEMS USED IN HYDROLOGICAL FORECASTING ACTIVITY. CASE STUDY: THE UPPER PART OF TUTOVA RIVER BASIN
}

\author{
A. MIHALCEA $A^{1,2}$
}

\begin{abstract}
Operational systems used in hydrological forecasting activity. Case study: the upper part of Tutova river basin. Flash floods are among the most dangerous natural hazards. In order to issue flash flood warning messages are taken into account information provided by several sources. The analysis of an event that took place in the upper part of Tutova river basin, on the 13th of May 2017 , was proposed in order to verify the accuracy of the products offered by the main systems used in flash floods forecasting activity. Following the analysis it can be observed that all the operational systems (ROFFG, SEEFFG, EFAS) forecasted a flash flood phenomena for Eastern part of the country, especially Tutova river basin, event that caused significant damages.
\end{abstract}

Keywords: flash floods, ROFFG, SEEFFG, EFAS, Tutova river basin.

\section{INTRODUCTION}

Flash floods are among the most dangerous natural hazards, these being generated by heavy rainfall in small basins, most of them being unmonitored hydrometric. These are among the natural disasters with a significant social, economic and environmental impact. Flash floods are characterized by a very short growth time and a high speed, so forecasting and warning activity of these phenomena is extremely difficult. The basis of the hydrological forecasts is the analysis of all the factors and processes that determine the formation of hydrological events (Diaconu C., Blaga O., Lăzărescu D., 1978). In order to issue flash flood warning messages are taken into account information provided by several sources.

In this paper I proposed the analysis of an event that took place in the upper part of Tutova river basin, on the 13th of May 2017, in order to verify the accuracy of the products offered by the main systems used in flash floods forecasting activity. The Tutova river basin is located in the Eastern part of the country (fig. 1). It is a right tributary of Barlad river, with a catchment area of 687 $\mathrm{km}^{2}$, length $=86 \mathrm{~km}$ and a maximum height of $503 \mathrm{~m}$. Tutova river basin crosses Bacau and Vaslui counties with un average flow about $0.9 \mathrm{~m}^{3} / \mathrm{s}$.

\footnotetext{
${ }^{1}$ Faculty of Geography, University of Bucharest, 1 Nicolae Bălcescu Blvd., 010041, Bucharest, Romania,mihalceandreea@gmail.com

${ }^{2}$ National Institute of Hydrology and Water Management, Romania
} 


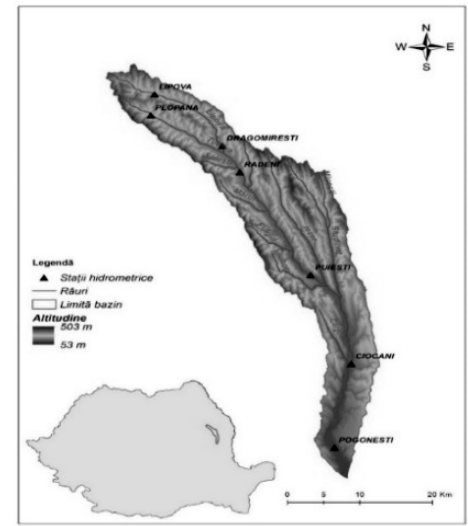

Fig. 1. Tutova river basin

\section{DATA AND METHODS}

Operative procedures for elaborating flash flood warnings are based on information provided by 3 main systems: ROFFG, SEEFFG, EFAS.

ROFFG - Romania Flash Flood Guidance System (fig. 2):

$\rightarrow$ ingests real-time radar and gauge precipitation date on an hourly update

$\rightarrow$ provides meteorological information (e.g. temperature and snow information during the winter months)

$\rightarrow$ the watersheds included in ROFFG system have an average area around $30 \mathrm{~km}^{2}$

$\rightarrow$ In Romania were delineated a number of 8851 watersheds.

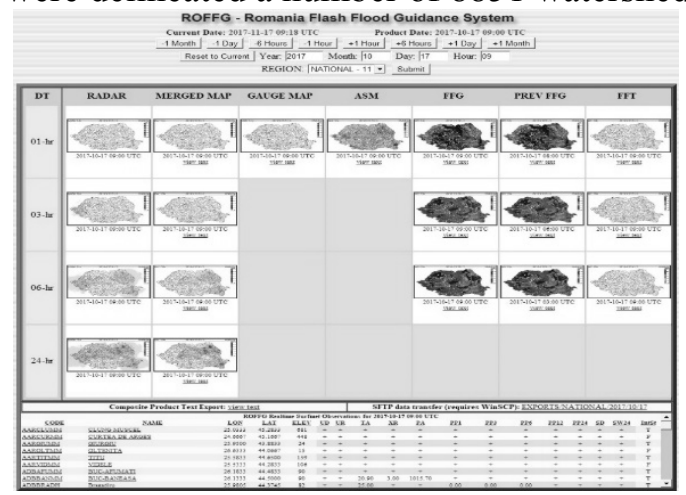

Fig. 2. ROFFG - web interface

SEEFFG - Southeast European Flash-Flood Guidance System (fig. 3):

$\rightarrow$ largely provides the same information as ROFFG system 
$\rightarrow$ the larger area for catchements: SEEFFG - around $100-150 \mathrm{~km}^{2}$ vs. ROFFG - around $30 \mathrm{~km}^{2}$

$\rightarrow$ the estimated rainfall using satellite products include rainfall forecast component based on ALADIN model.

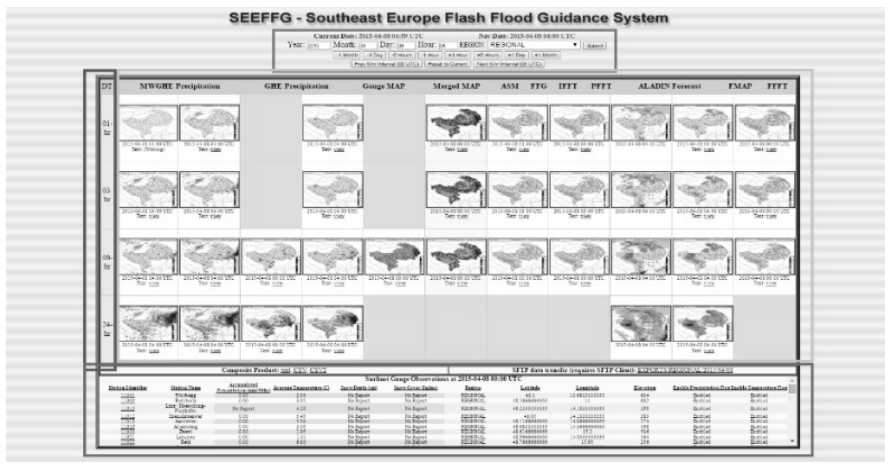

Fig. 3. SEEFFG - web interface

EFAS - European Flood Awareness System (fig. 4):

$\rightarrow$ it is the first monitoring and forecast operational system for floods at european level

$\rightarrow$ it was designed in the first instance for medium and large size river basins and lead time up to ten days.

$\rightarrow$ the dedicated flash-floods component from EFAS includes 2 products:

- Reporting points - showing the forecasted probability [\%] of surface runoff index to exceed a 5 or 20 year return period magnitude.

- $\quad$ Affected Drainage Area - highlights the upstream river network which contributes to each reporting point

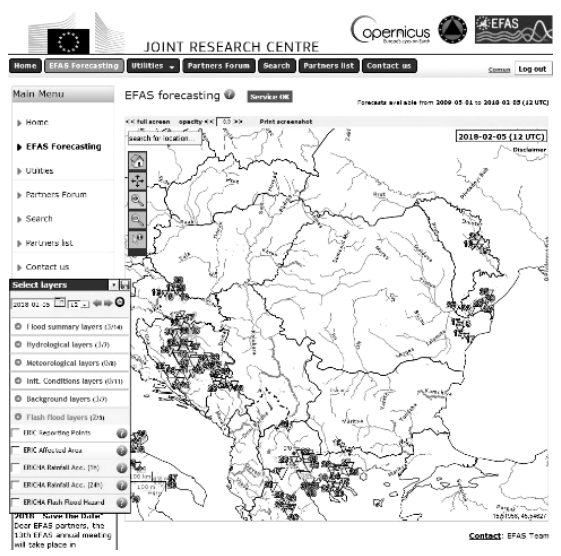

Fig. 4. Efas - web interface 


\section{RESULTS}

ROFFG system is designed to integrate real - time data from various hydrometeorological sources and to evaluate a number of diagnostic indices that are pertinent to the occurrence and development of natural flash floods (Sperfslage, Spencer, Georgakakos, 2010).

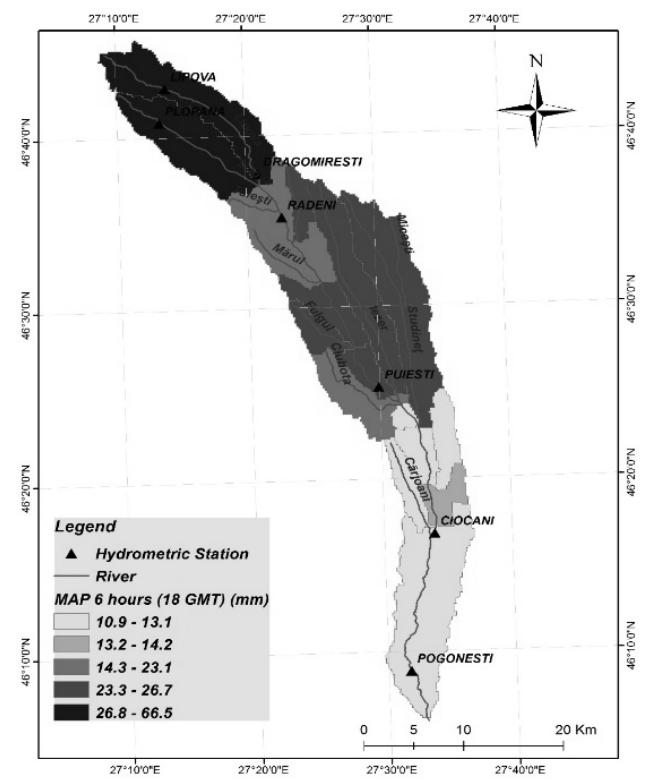

Fig. 5. ROFFG - MAP product for Tutova river basin, on 13.05.2017

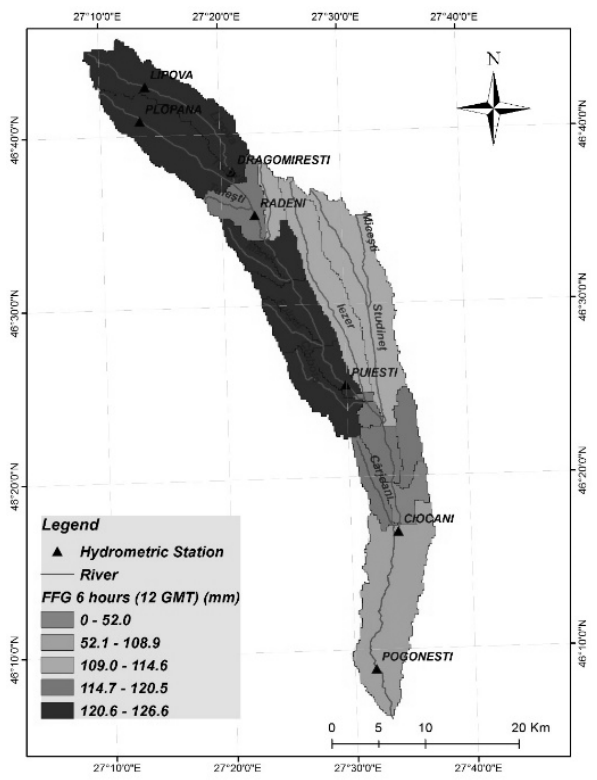

Fig. 6. ROFFG - FFG product for Tutova river basin, on 13.05.2017

After analyzing the products of the Romanian Flash Flood Guidance System (ROFFG), we can see that the heavy rainfall are estimated about $65 \mathrm{~mm}$ (fig. 5) within 6 hours for the researched study area, which leads to a high degree of flash floods formation.

The FFG value indicates the total volume of rainfall over the given duration which is just enough to cause bankfull flow at the outlet of the draining stream (Georgakakos, 2005).

In figure 6, it can be seen that for the low area of the Tutova river basin it is necessary to rain about $50 \mathrm{~mm}$ to cause a flash flood.

In the above images it can be observed that the SEEFFG products indicate large amounts of precipitation for the studied area (about 100mm). Forecast Mean Areal Precipitation (FMAP) products (fig. 7) are generated from the NWP precipitation forecasts for each catchment. 


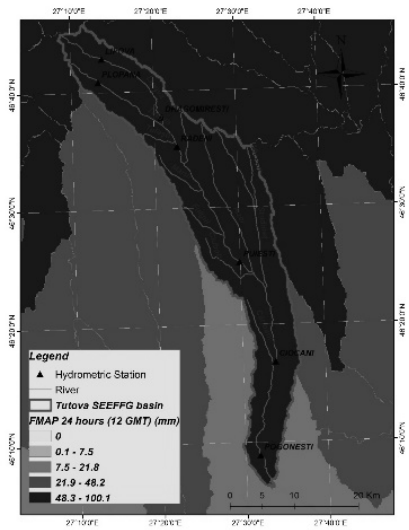

Fig. 7. SEEFFG FMAP product for Tutova river basin

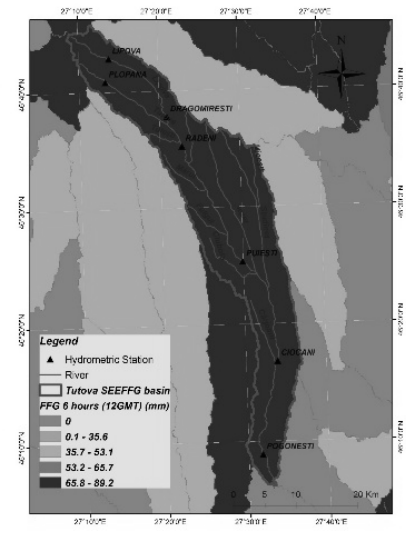

Fig. 8. SEEFFG FFG product for Tutova river basin

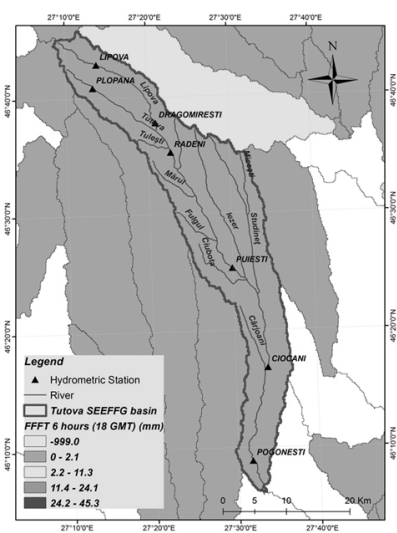

Fig. 9. SEEFFG FFFT product for Tutova river basin

The FFG is the key product in the determination of flash flood potential when using FFG system. For Tutova river basin, the FFG values are between 65 $90 \mathrm{~mm}$ (fig. 8), the amount of precipitation that is just enough to cause bankfull flow at the outlet of th catchment. FFFT (fig. 9) provides the forecaster with an idea of regions forecasted to be concern for flash flooding based on the difference of FMAP forecasters of mean areal rainfall and the corresponding current FFG (WMO, 2017).

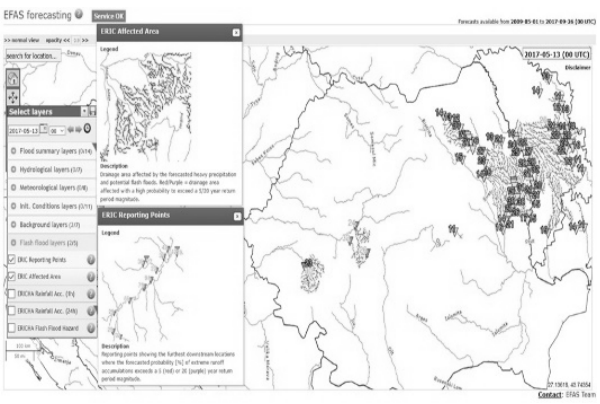

Fig. 10. EFAS product - 13/05/2017 at 00

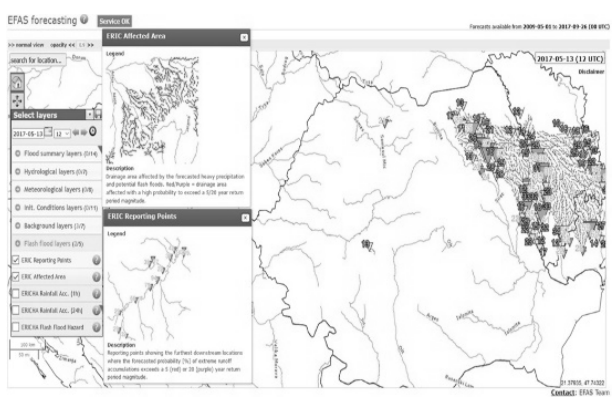

Fig. 11. EFAS product-13/05/2017 at $12^{\circ}$

The European Flood Awareness System provides probabilistic flood forecast information more than 48 hours in advance to National Authorities. It currently incorporates multiple weather forecasts from three different weather services, real-time weather observations from more than 5000 stations across Europe and real-time hydrological stations from more than 500 stations. 
For our study area, it can be observed on figures 10 and 11, points marked with purple. These points are generated when the probability of an event to exceed a 20 -year return period is greater than $10 \%$.

\section{CONCLUSIONS}

Following the analysis we can see that that all the operational systems forecasted a flash flood phenomena for Eastern part of the country, especially Tutova river basin. ROFFG system indicate heavy rainfall between $50-100 \mathrm{~mm}$ within 6 hours for the researched study area. All the SEEFFG system products lead to a high degree of flash floods formation also. The points marked with purple that can be observed on the EFAS system's web interface indicate the possibility of flash flood occur in Tutova river basin.

According to the specific observations and prediction assessment, the National Institute of Hydrology and Water Management, first issued the yellow code message for the study area, then issued red code based on the information received from the field (fig. 12).

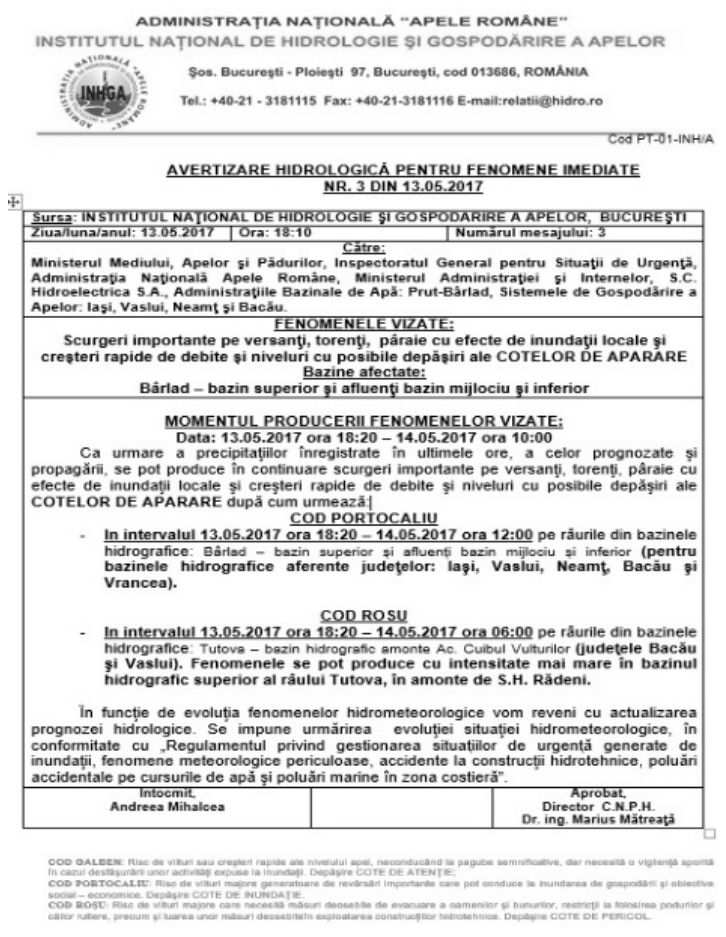

Fig. 12. Flash-Flood Warning issued by NHFC

The flash flood phenomena occurred in Tutova river basin, on 13 May 2017, the precipitation accumulations were at Plopana hydrometric station about 90 
1/mp and Lipova about $95 \mathrm{l} / \mathrm{mp}$, so the flood formed in the upper basin of the Tutova river caused significant damages (fig. 13, 14).

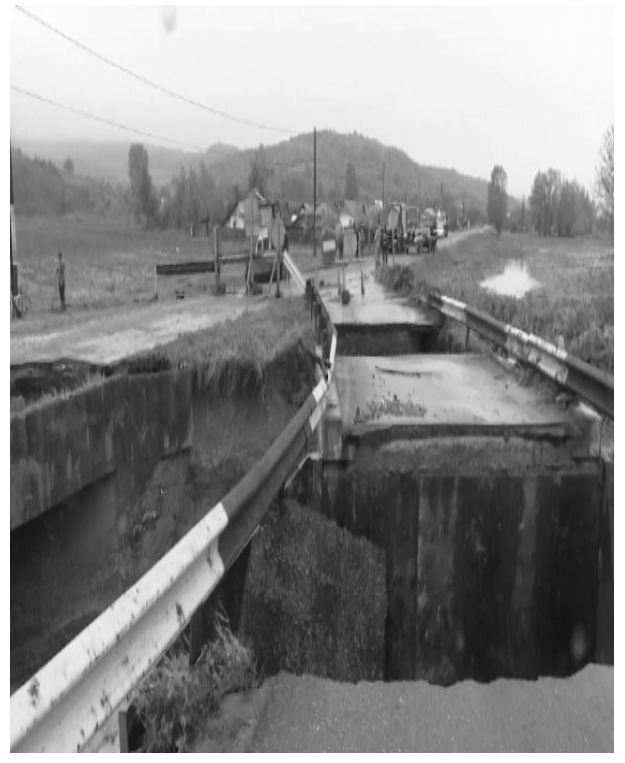

Fig. 13. Damages in Lipova Village

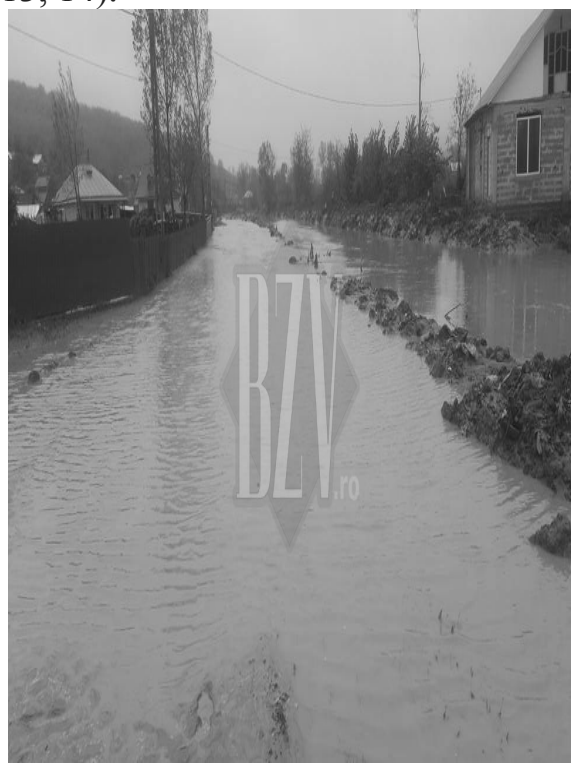

Fig. 14. Tutova River

\section{REFERENCES}

1. Diaconu, C., Blaga, O., Lăzărescu, D. (1978), Hidraulică şi hidrologie, Editura Tehnică, Bucureşti

2. Georgakakos, K.P. (2005), Modern Operational Flash Flood Warning Systems Based on Flash Flood Guidance Theory: Performance Evaluation. Proceedings, International Conference on Innovation, Advances and Implementation of Flood Forecasting Technology, Bergen - Tromsø, Norway, pp. 1-10

3. Sperfslage, Spencer, Georgakakos (2010), Romania Flash Flood Guidance System (ROFFG) - user guide, HRC

4. World Meteorological Organization (2017), South East Europe flash flood guidance system (seeffgs) - user guide, prepared by Petra Mutic 